\title{
A Corpus-based Study of The Specificity ADJECTIVES SPECIFIC AND PARTICULAR IN ACADEMIC WritTEN ENGLISH: EVIDENCE FROM THE BAWE Corpus
}

\begin{abstract}
The article presents an exploratory study on the use of two specificity adjectives: specific and particular in the corpus of British Academic Written English, with supplementary frequency data obtained from the British National Corpus and a corpus of English Research Articles. The Sketch Engine and WordSmith Tools 6.0 are employed to find out to what extent the two near-synonyms are interchangeable by exploring their overall and discipline frequency, potential synonyms and lexico-grammatical behaviour, including lexical bundles. The results reveal that despite certain similarities in the use of specific and particular in academic written English, such as sharing some of the synonyms or lexicogrammatical patterns, it is definitely specific that is more frequent in hard science prose, has a more diverse lexico-grammatical profile and denotes a specificity that is scalar in its nature and context-specific rather than universal.
\end{abstract}

Keywords

specificity adjectives; specific; particular; academic written English; BAWE

\section{Introduction}

Empirical investigations of English academic discourse based on analysing authentic texts produced by members of the community have evidenced that the lexical choices made in academic contexts tend to be different from those made by average users of the same words in non-specialized discourse. This seems to be equally the case with nouns (e.g. plane in mathematics refers to a flat, two- 
dimensional surface that continues in all directions but denotes a type of aircraft in common parlance) as with other content word classes, including adjectives. Unfortunately, as Tucker (1998: 7) claims, the latter "have generally received less attention than the other open set classes," even though they represent around $20 \%$ of potential academic words (Paquot 2010: 59). Previous studies of adjectives in academic English were either general (e.g. Hinkel 2004, Biber 2006, Biber and Gray 2016) or concerned with such classes of adjectives as evaluative (e.g. Swales and Burke 2003, Ağçam and Özkan 2015) or epistemic (e.g. Warchał 2015, Ağçam 2014). A possible reason behind this relative neglect is the assumption that scientific writing is intended to communicate ideas "as simply as possible to minimize the volume and maximize the meaning", which, as OkuliczKozaryn (2013: 679) argues, is seriously impeded by adjectives. It should be noted though that adjectives, owing to their inherently descriptive nature often help to convey the details of scientific information and "play important cohesive, classificatory and evaluative roles" in academic discourse, which makes them an interesting object of study (Hinkel 2004: 211). Yet, the nuances of meaning expressed in academic prose require a high degree of lexical precision that is often achieved not by simply choosing between semantically distinct items but rather by selecting only one from among many near-synonyms.

The semantic class of adjectives which seem to significantly contribute to the informational density of academic discourse involves adjectives of specificity, represented by such terms as particular, specific or certain (see Enç 1991; Ghesquière 2014). Rather than simply characterizing the referent of a nominal expression, they also serve the particularizing function, which as Ghesquière (2014: 180) argues, allows them to attribute "the quality of specificity or detail to the NP referent." This can be illustrated by the noun phrase a particular event, which is specific as it refers to one unique, though indefinite instance of the type event, whereas the noun phrase an event simply refers to any possible instance. Yet, it should be remembered that since "specificity involves only the speaker's knowledge" of which particular entity is referred to with a given nominal, its interpretation is often context-dependent, as this is the reader's only route of access to what the speaker has in mind (Ionin 2006: 8). Thus, it is worth investigating whether some of these contexts can actually be shared by selected semantically similar specificity adjectives, both to facilitate their understanding and avoid their misuse in academic communication.

This study focuses on two specificity adjectives: specific and particular, whose lexical source meanings are very similar but certainly not identical (see Ghesquière 2014). It explores the contextual nuances of their use by proficient writers of academic prose in the 6.5-million-word corpus of British Academic Written English (BAWE). The aim is to compare the two near-synonyms with regard to their overall and discipline frequency, synonym candidates as well as grammatical and collocational behaviour, including lexical bundles. Additionally, the frequency analysis has been supplemented with data obtained from the British National Corpus (BNC) and a corpus of English Research Articles (ERA). The results of the 
quantitative analysis will provide a basis for discussing the extent to which specific and particular serve to establish a similar type of general and/or unique reference, and can thus be considered as interchangeable in academic written English.

\section{Specific and particular as two specificity adjectives}

Adjectives belong to core grammatical features, in the set of which they represent open word classes that have independent lexical meaning, as in principle adjectives describe the attributes of objects, identifying or sub-classifying them thus, and therefore constitute important building blocks of sentences (see Biber \& Gray 2016; Tucker 1998). They also belong to the prevalent grammatical features of written academic English (see Biber et al. 1999). As previous research indicates (e.g. Biber et al. 1999, Biber et al. 2002), central adjectives are gradable and can be inflected to express degree of comparison (e.g. small - smaller - smallest), serve as descriptors and/or classifiers (delimiting a noun's referent but also describing it), and fulfil attributive (e.g. new information), predicative (e.g. she is smart) and five other syntactic roles (post-posed modifiers, noun phrase heads, clause linkers, free modifiers, exclamations). Additionally, "adjectives [...] make up a large proportion of the vocabulary of evaluation" and can "take on extended meanings in specialised fields," as exemplified by the adjective nuclear that has "extended senses in astronomy, biology, medicine, psychoanalysis, sociology, linguistics and phonetics" (Paquot 2010: 20).

One of the problems that adjectives pose is their semantic organization. As Morzycki (2015: 44) explains, some classifications are motivated by syntactic goals, whereby adjectives are assigned to categories in relation to their position in the sentence. Other classifications are motivated by typological considerations, whereby adjectives are grouped based on the concepts that are lexicalized with them. In this classificatory maze, certain taxonomies appear as subjective when juxtaposed with other semantic groupings of adjectives. This also concerns how the adjectives specific and particular analysed here are semantically categorised. Biber et al. (1999: 513) list them among relational adjectives that are very frequent in academic prose (e.g. general, basic, whole), where they serve to delimit "the referent of a noun, particularly in relation to other referents". Together with affiliative and topical adjectives, the relational ones create the superordinate category of classifiers, many of which are non-gradable but restrictive and often also descriptive in their nature, though the latter characteristic is somewhat less typical of relational classifiers. Quirk et al. (1985: 430), in turn, mention that specific and particular represent restrictive adjectives, which "restrict the reference of the noun exclusively, particularly, or chiefly" and are alternatively classified by Fragaki (2009: 11) as "specializing adjectives."

By comparison, Enç (1991) and Ghesquière (2014: 180) classify specific and particular as the so-called "specificity adjectives," which make indefinite NPs specific, that is, "referring to one unique, yet indefinite instance". As regards their 
distributional characteristics, the adjectives discussed above can be preceded by definite determiners (e.g. the specific details she wanted to convey, this particular feature), which correlates well with their disambiguating potential. They can also combine with various indefinite determiners (e.g. three specific girls, some particular users), establishing in this way indefinite identification, which nevertheless is interpreted as specific. In Ghesquière's (2014: 179-208) discussion of the specificity adjectives, specific and particular are characterized as conveying descriptive meanings, whereby the denoted properties are conceptualized as degrees, which in turn licenses the pre-modification of the adjectives themselves (e.g. highly specific qualities). They can also function as secondary determiners that help to further identify an NP by relating its referent to other elements that can be retrieved from the discourse context or found in a reference set (e.g. the specific characteristics of developing countries discussed here). Additionally, the specificity adjectives, mainly particular, can function as noun-intensifiers (e.g. I have a particular fondness for this restaurant) and classifiers, especially specific (e.g. specific difference to name the characteristic that is unique to a given species).

Given the above characteristics, specific and particular are regarded as synonymous in that they both relate to only one person or thing and not anyone or anything else, both convey the idea of precision or exactness when pertaining to something or someone, and both allow for a definiteness of expression that prevents ambiguity. Yet, aside from their semantic similarity, the two adjectives have some distinctly different senses, for instance, "remarkable, noteworthy; peculiar, singular" for particular (OED 7.b) or "of or pertaining to, connected with, etc., a distinct species of animals or plants" for specific (OED 5). It is thus worth disentangling how specific and particular assist in communicating scholarly research, especially that they are both included in the set of 180 adjectives that are "reasonably frequent in a wide range of academic texts" and together with other word classes make up the Academic Keyword List (Paquot 2010: 61). Additionally, specific is among the most frequent words (Sublist 1) of the Academic Word List (Coxhead 2000). The importance of the two adjectives for academic communication is also evidenced by their frequency of occurrence in the BNC, which is the highest in the academic section of the written register, as shown in Table 1.

Table 1. Frequency of specific and particular in the BNC

\begin{tabular}{|l|c|c|c|c|c|c|c|c|}
\hline & Total & spoken & fiction & magazine & newspaper & non-acad & acad & misc \\
\hline specific & 11180 & 594 & 163 & 354 & 255 & 2358 & 4378 & 3078 \\
\hline particular & 21733 & 2129 & 984 & 753 & 518 & 4417 & 7787 & 5145 \\
\hline
\end{tabular}

\section{An overview of the analytical aspects of the study}

This corpus-based investigation adopts an empirical approach to the description of how the adjectives specific and particular behave in academic written English. Following Tognini-Bonelli (2001: 2), "the starting point is actual authentic 
data", from which "observations of the actual instances" are derived regarding different aspects in terms of which the contextual nuances of the words use can be analysed. To assist in identifying the semantic-grammatical profiles of the two adjectives, five main procedures of corpus analysis were applied.

Frequency analysis was used to reveal important "repeated, taken-for-granted choices" in the use of specific and particular, understood as both regularities and possibly also exceptions (Hyland 2015: 300). Its results allowed to evidence the relative significance of the discussed lexemes in the writers' lexical repertoire of academic words. This, in turn, helped to determine which of the two adjectives contributes more effectively to the construction of meanings in academic prose and to the negotiation of the writers' disciplinary identity reflected in the discipline frequencies of occurrence.

Collocation analysis concentrated on "the linguistic phenomenon whereby a given vocabulary item prefers the company of another item rather than its 'synonyms' because of constraints which" exist on the level "of usage" (Van Roey 1990: 48). It was thus concerned with the combinations of specific and particular with lexical items occurring "in statistically significant ways" within a few words to the adjectives' right and left in running text, as a result of which the two components merged into word pairs, not necessarily limited by grammar boundaries (Lewis 2000: 132). The strength of mutual attraction between specific and/or particular and the accompanying words was identified based on statistical association measures (e.g. mutual information MI, t-test or the Dice coefficient), not on simple co-occurrence frequency counts, which allowed to extract collocations that are both strong and salient rather than merely accidental. The identification of the common collocates of specific and particular was intended to reveal which complex segments of meaning in written academic English are successfully communicated by either one or the other adjective. As Bartsch (2004: 20) claims, "many collocations are highly domain specific" and thus their command is "the key to mastery of specialist communication". Also, providing contextual clues as to which lexical items typically trigger the selection of either specific or particular helped to disambiguate their individual senses.

The analysis of lexico-grammatical patterns was motivated by the fact that "the degree of semantic similarity between two linguistic expressions depends on the similarity of the linguistic contexts in which they appear" (De Simone et al. 2015: 31). It enabled the exploration of the typical and frequent grammatical relations between specific and particular and their most salient collocates, revealing the syntactic dependency context of the word pairs. The aim was to highlight important discursive and contextual properties of the two adjectives that effectively contribute to the construction of semantic networks of meaning relations in written academic English

Cluster analysis revolved around 'clusters', defined by Scott $(1996: 41,35)$ as "words which are found repeatedly in each other's' company", representing "a tighter relationship than collocates, more like groups or phrases". They constitute a considerable proportion of spoken and written discourse, to the construction of which 
they contribute by being "stored and retrieved whole from memory at the time of use, rather than being subject to generation or analysis by the language grammar" (Wray and Perkins 2000: 1). The conventionalized linguistic expressions have been explored under a variety of other labels, including, among others, 'lexical phrases' (Nattinger 1988), 'multiword lexical units' (Cowie 1992), 'fixed expressions' (Moon 1992), 'formulaic expressions' (Simpson 2004), 'chunks' (O'Keeffe et al. 2007), 'formulaic sequences' (Schmitt and Carter 2004), $n$-grams' (Cheng et al. 2009), or 'multiword units' (Greaves and Warren 2010). When discussed under the term 'lexical bundles' (Biber et al. 2004), they are characterized as very common in speech and writing, not idiomatic and thus transparent in their meaning, usually not complete in their structure but rather bridging different structural units (Biber and Barbieri 2007: 269). In academic prose, as Biber et al. (1999: 992) note, most lexical bundles "are building blocks for extended noun phrases or prepositional phrases", such as the extent to which or at the end of. The identification of such recurrent contiguous multi-word sequences involving specific and particular allowed to provide direct insight into the conventionalized ways of framing meaning in linguistic forms in specific contexts, revealing the role that each adjective plays in the shared knowledge and communicative competence of the investigated professional discourse community.

Finally, a distributional thesaurus was used to represent "semantic relatedness between" specific and/or particular and other words by looking at their distribution to see if they appear in similar contexts, that is, if the lexical items they are typically accompanied by or syntactically linked with are approximately identical (Padró et al. 2014: 2964). Determining the degree of similarity between the distributional contexts of specific and/or particular and other words with comparable grammatical and collocational behaviour helped to show the extent to which the two adjectives are interchangeable in academic written English.

\section{Material and method}

Data for the present study are derived from the BAWE corpus developed at the Universities of Warwick, Reading and Oxford Brookes, UK. As detailed by Nesi (2011: 213), "the corpus consists of just under 3000 [university] student assignments of good standard (6,506,995 words), at four levels [of study] and in many disciplines." The corpus texts range in length from about 500 to 5000 words, represent 13 different genres and cover such disciplinary areas as Arts and $\mathrm{Hu}-$ manities, Social Sciences, Life Sciences and Physical Sciences, altogether representing 35 disciplines $(B A W E, 2016)$. All collected assignments were written by native or near-native speakers of English and received merit or distinction grades, which makes them representative of proficient academic writing (Nesi 2011: 220). Supplementary research data on the frequency of both adjectives were obtained from the BNC, which contains about 100 million words of mostly written texts (including over 15 million words in the academic section) repre- 
senting a wide cross-section of British English (What is the BNC? 2015). The analysis was also supplemented with frequency data drawn from a corpus of 1247 research articles (ERA) written by authors with a native-like command of English which were taken from internationally recognised journals in the fields of life and social sciences, with a total of 10,115,685 running words.

The main investigative technique was the comparison of two seemingly identical adjectives: specific and particular. The main corpus tool was the Sketch Engine, which offers a number of functions for exploring how words behave in various contexts, such as the word sketch summarizing grammatical and collocational behaviour, as well as a concordancer and distributional thesaurus (Kilgarriff et al. 2014). The system also allows to compare two words, specifying their shared and different collocational context, which is useful in differentiating between nearsynonyms (Radziszewski et al. 2011: 240-241). Additionally, WordSmith Tools 6.0 (Scott 2012) was used to search the BAWE corpus and perform a cluster analysis to extract the most frequent lexical bundles of the two adjectives.

\section{Results and discussion: specific and particular in BAWE}

The following sections report the corpus analysis results for the adjectives specific and particular. Where necessary and practicable, statistical significance is reported at the alpha level of 0.05. The illustrations in Figures 1, 2, 3 and 4 come from the Sketch Engine website. ${ }^{1}$

\subsection{Overall frequency}

Frequency analysis revealed 1955 occurrences of specific (234.51 per million words [pmw]) and 1765 occurrences of particular (211.72 pmw), which indicates that the former adjective is about $10 \%$ more frequent in the BAWE corpus than the latter. This preference for specific in written academic prose is also reflected in the ERA corpus, where it occurred 4267 times (421.82), which is about 30\% more in comparison to only 2913 instances of particular (287.96). These findings may imply a wider collocational range and a more diverse semantic-grammatical profile of specific.

As can be deduced from Table 1 (see Section 2), there is a reverse situation in the $\mathrm{BNC}$ corpus, where after excluding the results obtained for its written academic section, the total frequency of specific is 6803 and that of particular is 13946, which makes the former adjective about $50 \%$ less frequent than the latter. Confronting this finding with what has been reported above on the overall frequency of both adjectives in the BAWE and ERA corpora, it can be said that in contrast to a large-scale collection of diverse text types, such as the BNC, in academic written English, it is specific rather than particular that contributes more to the communication of scientific information. 


\subsection{Discipline frequency}

As Table 2 indicates, there are striking differences between specific and particular regarding their relative frequency of occurrence in the four disciplinary areas represented by the BAWE texts. ${ }^{2}$ The reported frequencies suggest that the factor of disciplinary variation affects the lexical choices between the two seemingly synonymous adjectives in academic written English. Specific is relatively most frequent in the life sciences, with the three highest relative frequency values found for biological sciences (209.90), psychology (172.70) and food sciences (129.30). Then there are the physical sciences, with the highest relative frequency values for chemistry (186.80), architecture (133.60) and physics (122.10). The next are the social sciences, with the highest relative frequency values for anthropology (182.50), health (146.80) as well as hospitality, leisure and tourism management (135.20). The lowest relative frequency of occurrence of specific was found in the arts and humanities, with the strongest presence of the adjective in linguistics (180.90), archaeology (115.90) and philosophy (58).

The distribution of particular across the academic disciplines of BAWE is markedly different, as the adjective tends to occur relatively more often in the discourse of soft rather than hard sciences. It is relatively most frequent in the social sciences, with the three highest relative frequency values found for anthropology (155), sociology (145.60) and health (138.30). Then there are the arts and humanities, with the highest relative frequency values for linguistics (180.90), archaeology (115.90) and philosophy (58). The next are the physical sciences, with the highest relative frequency values for architecture (314.60), computer science (124.90) and physics (105.70). Finally, there are the life sciences, where the presence of particular is the strongest in psychology (175.70), agriculture (89.40) and food sciences (64.70).

Table 2. Frequency of specific and particular across the BAWE disciplinary areas

\begin{tabular}{|l|c|c|l|c|c|}
\hline \multicolumn{3}{|c|}{ specific } & \multicolumn{3}{c|}{ particular } \\
\hline Disciplinary area & Freq & Relative freq & Disciplinary area & Freq & Relative freq \\
\hline Life Sciences & 615 & 148.20 & Social Sciences & 619 & 109.10 \\
\hline Physical Sciences & 370 & 95.80 & Arts and Humanities & 473 & 99.70 \\
\hline Social Sciences & 588 & 93.60 & Physical Sciences & 339 & 97.30 \\
\hline Arts and Humanities & 382 & 72.70 & Life Sciences & 334 & 89.20 \\
\hline
\end{tabular}

The higher relative frequency of specific in the discourse of life (119.78) rather than social sciences (70.48) was also observed in the ERA corpus. Similarly, the relative frequency of particular was higher in the discourse of social (147.35), not life sciences (68.42), as reported above for the BAWE corpus. It thus seems that specific contributes more to the concerns of hard science prose, which Biber and Gray (2016: 2) define as "discovering and documenting new natural phenomena and processes," whereas particular adds more to the interpretation and description of already familiar ideas, relationships and human experience, around 
which soft science prose revolves. By comparison, the distribution pattern of the two adjectives across the academic sub-sections of the BNC is somewhat different, as they both are relatively most frequent in the social sciences (respectively, 207 for specific and 227.02 for particular) and law (respectively, 171.73 and 215.81). As for the other BNC academic disciplines, specific is relatively frequent also in medicine (87.93), the humanities (72.95), the natural sciences (58.96) and engineering (26.41). The order of these disciplines is different for particular, which is relatively frequent in the humanities (92.78), engineering (35.30), the natural sciences (32.93) and medicine (21.16).

\subsection{Lexico-grammatical patterns}

Figure 1 shows six patterns (see the underlined labels in blue) of the grammatical and collocational behaviour that are shared by specific and particular in the BAWE corpus.

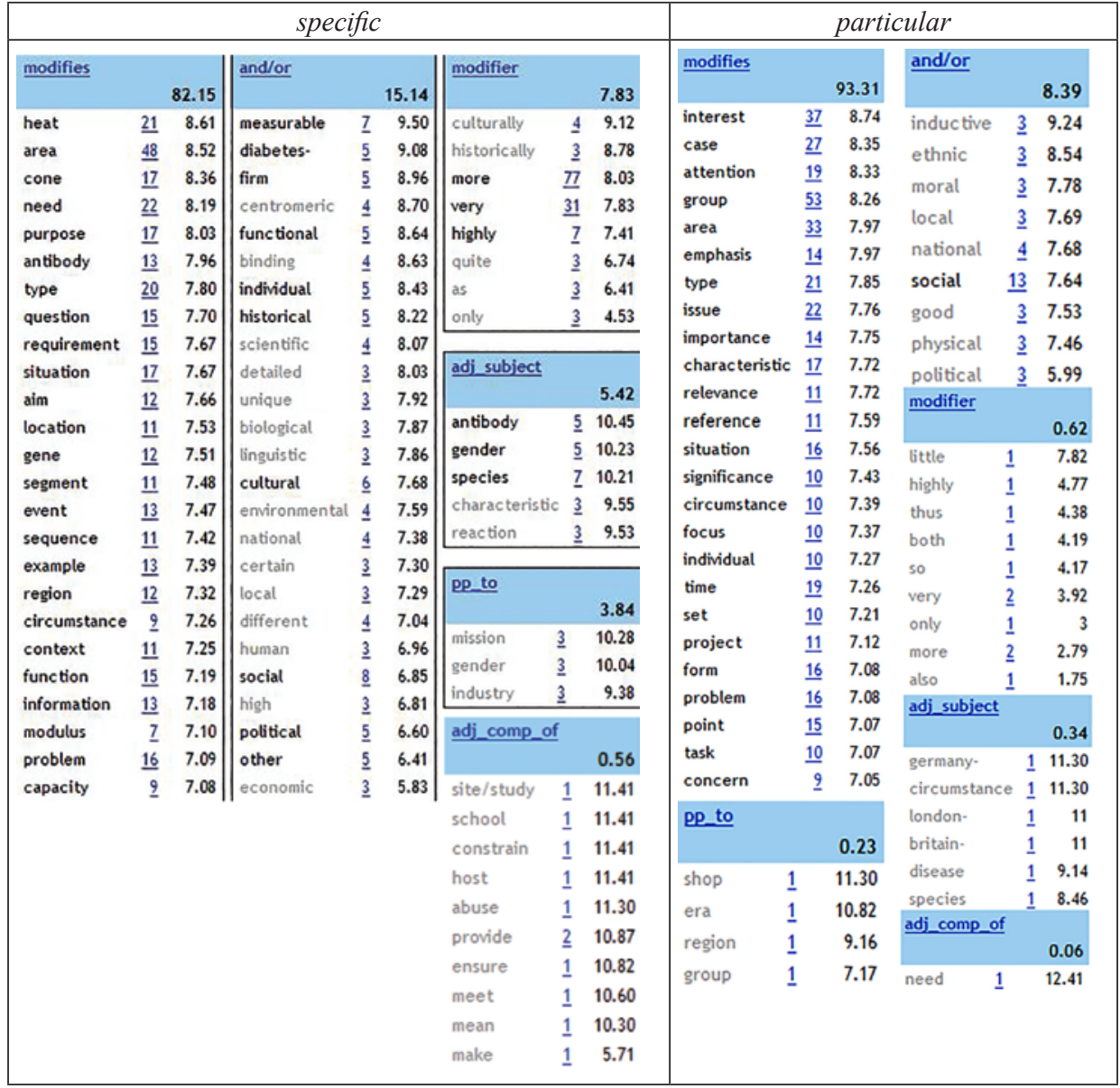

Figure 1. Lexico-grammatical patterns shared by specific and particular in BAWE 
Both specific and particular most frequently function as modifiers of nouns, which is commonly reported of adjectives in academic prose, where they "pack additional information into noun phrases" (Biber et al. 1999: 506). Specific enters the modifier + noun pattern 1606 times, which accounts for $70.25 \%$ of all its lexico-grammatical constructions. The pattern is significantly more productive in the case of particular $[\mathrm{t}(3758)=15.324, \mathrm{p}<0.001, d=0.37]$, which is found in it 1647 times $(90.39 \%)$. The relatively higher popularity of the attributive use of particular correlates well with its higher frequency - in comparison with specific - in soft science prose, where attributive adjectives are quite common, as well as with its lower frequency in hard science prose, where such adjectives are less common (Biber and Gray 2016: 8-9). When specific and particular are found in this pattern, as Francis et al. (1988: 384-386) observe, they typically convey their ungraded senses. Both function then as secondary determiners that "contribute to NP identification by instructing the hearer to relate the NP referent to other elements", which may take three different forms (Ghesquière 2014: 185). In (1) specific construes a cataphoric relation between the NP and a reference set available in the following discourse, which illustrates the individuating use. In (2) particular highlights the link between the NP and its discourse referent signalled by the possessive pronoun her, which exemplifies the linking use and may be paraphrased using the phrase peculiar to. In (3) particular strengthens the meaning of that by pointing to just one customer and not another one, which illustrates the focusing use (see Ghesquière 2014: 185-191).

(1) In conclusion, there is no specific definition of entrepreneurs. They can be defined psychologically [...], economically [...], socially [...] or a combination of all three (text_1583)

(2) she would have to ensure that her particular observations actually represent reality (text_282)

(3) it was a customized solution for that particular customer (text_1836)

In the second most popular pattern: and/or, the adjectives are conjoined with other adjectives by means of and, or, or a comma. As for specific, the pattern is represented by 296 tokens $(12.95 \%)$ and for particular, by 153 tokens $(8.40 \%)$, which makes a statistically significant difference $[\mathrm{t}(3758)=4.483, \mathrm{p}<0.001, d=0.18]$ :

(4) because it looks at a particular and specialised area of archaeology that has (text_302)

(5) occurrences or hypothetical responses, specific, detailed answers or (text_46)

In the third most popular pattern the adjectives are modified by adverbs. Specific 
occurs in such constructions 153 times (6.69\%), where it is modified mainly by more ( 77 tokens), very (31 tokens) and highly ( 7 tokens). The scalar nature of particular is significantly less marked [t(3758) $=9.687, \mathrm{p}<0.001, d=0.34]$, as it enters the pattern (example 6 ) only 11 times $(0.61 \%)$. This finding further confirms that in the BAWE corpus, particular tends to be used as an ungraded adjective "that never or rarely follows a grading adverb and which does not have a comparative or superlative form" (Francis et al. 1998: 363). Specific, in turn, is more likely to exhibit descriptive modifier uses, approximating thus the senses of exact, detailed or precise, when used objectively (7), or indicating the peculiarity or remarkability of the NP referent, when used subjectively (8) (see Ghesquière 2014: 181-185).

(6) the action of putting things in a very particular box (text_1766)

(7) searching for more specific clinical signs which indicate IE (text_196)

(8) what is to be done in certain highly specific circumstances (text_2672)

Next, there is the adj_subject pattern, in which the adjectives function as predicative expressions denoting characteristics of the subject. Specific enters the pattern 106 times (4.64\%) and particular, only 6 times $(0.33 \%)$, which makes a statistically significant difference $[\mathrm{t}(3758)=8.262, \mathrm{p}<0.001, d=0.29]$. The fairly infrequent use of particular in this pattern is not surprising, since according to Francis et al. (1998: 389), the adjectives that are more usually found in it are graded, whereas in the majority of its occurrences in the BAWE corpus, particular is used as an ungraded adjective, functioning as an attributive rather than predicative modifier. Thus, it seems that it is specific, rather than particular, that plays a role in providing a frame for the intellectual claims made in academic prose (see Biber et al. 1999: 518):

(9) The reaction conditions are specific and changing a condition will affect (text_1393)

(10) The system in Germany is also particular because its branch associations (text_803)

The fifth is the $p p \_t o$ pattern, in which the adjectives form a prepositional phrase with to that links the following noun with its properties that precede the adjective. As Francis et al. (1998: 469) claim, when specific or particular are used in this pattern, they "indicate that something occurs or is found in a specific place, or among specific people, or that something is restricted to a specific situation", as illustrated by (11) and (12). The frequency reported for specific is 75 tokens $(3.28 \%)$ and for particular, only 4 tokens $(0.22 \%)$, which again makes a statistically significant difference $[\mathrm{t}(3758)=6.961, \mathrm{p}<0.001, d=0.24]$ : 
(11) produce feelings of distance or coolness specific to the Verfremdungseffekte (text_109)

(12) unusual behaviour that might be caused by social circumstances particular to the shop (text_8)

The last pattern that the adjectives share is adj_comp_of, in which they serve as adjectival complements: $11(0.48 \%)$ occurrences for specific and only $1(0.05 \%)$ for particular, which makes a statistically significant difference $[\mathrm{t}(3758)=2.499$, $\mathrm{p}=0.013, d=0.08]$ :

(13) deliver packages that meet specific, individual, consumer needs (text_1706)

(14) nutritional needs particular to certain patient groups (text_1722)

A complementary set of word sketches provided additional data about the grammatical and collocational behaviour of both adjectives, revealing seven additional though infrequent patterns for specific and none for particular, which are shown in Table 3. These findings indicate that the former adjective shows a greater functional variation in the BAWE corpus, where altogether it serves thirteen different grammatical functions in comparison to only six performed by particular. In fact, the lexico-grammatical profile of particular overlaps with only $46 \%$ of the patterns entered by specific, and does not include any constructions that would be exclusive to this adjective.

Table 3. Additional lexico-grammatical patterns of specific in BAWE

\begin{tabular}{|l|c|c|l|c|c|}
\hline \multicolumn{1}{|c|}{ Pattern } & Freq & $\%$ & \multicolumn{1}{c|}{ Pattern } & Freq & $\%$ \\
\hline pp_for & 13 & 0.57 & pp_at & 2 & 0.09 \\
\hline np_adj_comp_of & 12 & 0.52 & pp_concerning & 1 & 0.04 \\
\hline pp_in & 6 & 0.27 & pp_like & 1 & 0.04 \\
\hline pp_about & 4 & 0.18 & & & \\
\hline
\end{tabular}

\subsection{Collocation analysis}

Table 4 shows twenty-five most common collocates of specific and particular in the BAWE corpus, ranked by the logDice association score (Rychlý 2008). The collocation candidates, representing different parts of speech, were identified within a span of five words on the left and right side and with the cut-off threshold of 3 occurrences in the corpus. 
Table 4. Twenty-five most common collocates of specific and particular in BAWE

\begin{tabular}{|l|c|c|c|c|l|c|c|c|c|}
\hline \multicolumn{7}{|c|}{ Specific } & \multicolumn{6}{|c|}{ particular } \\
\hline collocate & freq & $\begin{array}{c}\text { T- } \\
\text { score }\end{array}$ & MI & $\begin{array}{c}\text { Log } \\
\text { Dice }\end{array}$ & collocate & freq & T-score & MI & $\begin{array}{c}\text { Log } \\
\text { Dice }\end{array}$ \\
\hline wavelength & 23 & 4.784 & 8.717 & 8.428 & of & 24 & 4.875 & 7.689 & 8.408 \\
\hline heat & 31 & 5.525 & 7.036 & 8.421 & interest & 37 & 6.016 & 6.513 & 8.364 \\
\hline areas & 35 & 5.832 & 6.151 & 8.143 & group & 53 & 7.174 & 6.104 & 8.328 \\
\hline needs & 36 & 5.908 & 6.039 & 8.103 & reference & 24 & 4.862 & 7.076 & 8.237 \\
\hline species & 30 & 5.390 & 5.975 & 7.945 & attention & 25 & 4.957 & 6.870 & 8.206 \\
\hline DNA & 20 & 4.427 & 6.635 & 7.864 & any & 66 & 7.961 & 5.644 & 8.079 \\
\hline area & 29 & 5.279 & 5.677 & 7.764 & area & 34 & 5.743 & 6.054 & 8.057 \\
\hline cones & 13 & 3.602 & 10.086 & 7.730 & emphasis & 19 & 4.327 & 7.129 & 8.015 \\
\hline binding & 15 & 3.847 & 7.271 & 7.696 & focus & 25 & 4.934 & 6.251 & 7.949 \\
\hline particular & 26 & 4.987 & 5.517 & 7.605 & relevance & 15 & 3.858 & 8.051 & 7.918 \\
\hline types & 19 & 4.289 & 5.969 & 7.582 & issue & 23 & 4.727 & 6.134 & 7.830 \\
\hline purpose & 17 & 4.068 & 6.229 & 7.575 & particular & 29 & 5.289 & 5.822 & 7.826 \\
\hline antibodies & 12 & 3.456 & 8.901 & 7.575 & within & 48 & 6.747 & 5.259 & 7.677 \\
\hline language & 31 & 5.425 & 5.286 & 7.571 & specific & 22 & 4.604 & 5.778 & 7.622 \\
\hline very & 45 & 6.501 & 5.021 & 7.550 & a & 746 & 26.338 & 4.808 & 7.582 \\
\hline site & 20 & 4.390 & 5.777 & 7.544 & characteristics & 17 & 4.063 & 6.123 & 7.577 \\
\hline target & 16 & 3.944 & 6.166 & 7.495 & or & 143 & 11.551 & 4.876 & 7.563 \\
\hline relation & 17 & 4.055 & 5.923 & 7.466 & situation & 20 & 4.391 & 5.787 & 7.559 \\
\hline within & 42 & 6.266 & 4.918 & 7.449 & circumstances & 13 & 3.567 & 6.570 & 7.465 \\
\hline general & 22 & 4.579 & 5.402 & 7.432 & country & 19 & 4.272 & 5.650 & 7.453 \\
\hline more & 100 & 9.597 & 4.634 & 7.420 & case & 33 & 5.577 & 5.105 & 7.425 \\
\hline each & 41 & 6.182 & 4.856 & 7.393 & importance & 18 & 4.156 & 5.620 & 7.399 \\
\hline genes & 13 & 3.567 & 6.576 & 7.392 & this & 189 & 13.208 & 4.671 & 7.395 \\
\hline groups & 22 & 4.573 & 5.327 & 7.392 & groups & 21 & 4.474 & 5.407 & 7.390 \\
\hline questions & 16 & 3.929 & 5.829 & 7.376 & type & 18 & 4.154 & 5.588 & 7.383 \\
\hline
\end{tabular}

There are only three strong collocations (see the italicized words above) which are common to both specific and particular. The first of them, ranked as the seventh in terms of its typicality, is the one in which the adjectives modify the noun area, as in (15) and (16). Yet, the respective values of the logDice indicate that area is a more significant nominal collocate of particular (8.057) than specific (7.764). The second strong collocate, ranked as the tenth most typical in the case of specific and as the twelfth in the case of particular, is the one in which they co-occur with the adjective particular in the and/or grammatical pattern, as in (17). Again, the respective values of the logDice show that particular is a more significant collocate of particular (7.826) than specific (7.605). This suggests that despite some degree of semantic similarity between the two words, they are distinct enough to function as paired adjectives in the and/or pattern, as in (18). The third strong collocate, ranked as the twenty-fourth in terms of its typicality, is the one in which the adjectives modify the noun groups, as in (19) and (20). The respective values of the $\log$ Dice reveal that groups is an only slightly more 
significant nominal collocate of specific (7.392) than particular (7.390). Yet, statistical significance was not observed for these scores.

(15) (concentrating on a particular area, such as sport or arts) (text_944)

(16) ministers, each responsible for a specific area of policy. (text_1214)

(17) explanations of a particular ritual or a particular myth (text_2690)

(18) discourses have in turn made this field "more specific and particular" (text 542)

(19) tackle health inequalities by targeting specific groups who are (text_198)

(20) intent that is targeted at particular groups of individuals (text_1201)

Another important finding is that among the most common collocation candidates of specific there are only two function words (within, each), which is by two thirds less than in the case of particular (of, any, within, $a$, or, this). This suggests that the former adjective more effectively contributes to conveying semantic information in academic prose, as it more readily collocates with content words, the majority of which are nouns $(N=19)$. As regards the semantics of the top content collocates of the two adjectives, their meanings are more general in the case of particular (e.g. situation, case, issue), and quite a few of them are observation nouns, for instance, interest, attention, focus. The latter finding testifies to the noun-intensifying role of the adjective, similarly as the fact that it often collocates with the negative quantifier any (see Ghesquière 2014: 200-201). As Traugott (2010: 15) claims, sentences like (21) are dialogic in nature and likely to produce a hedging effect, as by using particular, the writer diplomatically contests the existence of a distinctive person and invokes an alternative. Another tentative conclusion that can be drawn from these results is that particular seems to belong more to the academic procedural vocabulary, which is "general or core language that allows the writer to fix the meaning of specific words" (Luzón Marco 1994: 163). Such words usually have little lexical content but, owing to their high indexical potential, help to negotiate specific concepts in many different contexts (see Luzón Marco 1999: 3). For example, in (22) the expression of particular interest in our study serves to explain the details of the discussed study result, emphasizing simultaneously why note should be taken of it. Similarly, in (23) the role of the phrase of particular relevance to is to make sense of and justify the writer's choice of the main subject matter of their text.

(21) the team members had not selected any particular person as their leader. Instead Pratap took the role of guiding the team rather than being a team leader. (text_1307) 
(22) This general result has been reported in much previous research; however, what is of particular interest in our study is that it holds even when all participants were asked to consider the same specific situation, that of a heavy academic workload. (text_67)

(23) The purpose of this report is to consider the rules of IHL that are of particular relevance to child soldiers in order to ascertain whether such rules are sufficiently adequate to address the participation and use of child soldiers in armed conflict. (text_1507)

By comparison, the content collocates of specific are more specialized or 'technical' in their meaning (e.g. wavelength, heat, species, DNA, cones, antibodies, genes), as illustrated by (24) and (25). This may result from the marked popularity of specific in such disciplinary areas as life and physical sciences which, according to Hyland (2016: 21), rework "experience technically by establishing a range of specialist terms which are ordered to explain how things happen or exist."

(24) how it can lead to four different types of wavelength specific cones (text_61)

(25) Even with the presence of specific antibodies there is little increase of monocytic bactericidal activity. (text_38)

It is also worth noting that these are definitely the properties described by specific "that are inherently conceptualized as degrees", as illustrated by (26), which is manifested by the fact that the adjective strongly collocates with "modifiers that measure the actual degree of a quality on a scale going up or down from a reference point" (Ghesquière 2014: 181). As can be seen in Table 4, the list of the words which collocate most strongly with specific includes two adverbs of degree (i.e. very, more) which are totally absent among the collocation candidates of particular.

(26) The company has to be very specific and prudent while deciding the source of finance (text_1304)

\subsection{Cluster analysis}

Table 5 shows the most frequent 3-word and 4-word clusters of specific and particular, arranged in the order of frequency of occurrence and italicized when shared by both adjectives. The clusters were extracted from the BAWE corpus by means of WordSmith Tools 6.0 (Scott 2012) with the minimum frequency level set to 10 occurrences, as a result of which the search yielded no instances of 4-word clusters of specific. It should be noted that all clusters including the phrase in par- 
ticular were excluded from the analysis as they did not constitute the adjectival uses of the word.

Table 5. The most frequent 3- and 4-word clusters of specific and particular in BAWE

\begin{tabular}{|c|c|c|c|c|}
\hline \multicolumn{3}{|c|}{ specific } & \multicolumn{2}{|l|}{ particular } \\
\hline No & Cluster & Freq & Cluster & Freq \\
\hline 1 & to a specific & 49 & of a particular & 88 \\
\hline 2 & of a specific & 36 & to a particular & 67 \\
\hline 3 & specific to the & 33 & in a particular & 65 \\
\hline 4 & in a specific & 33 & for a particular & 48 \\
\hline 5 & to the specific & 25 & of the particular & 32 \\
\hline 6 & of the specific & 22 & at a particular & 31 \\
\hline 7 & for a specific & 21 & of particular interest & 28 \\
\hline 8 & at a specific & 19 & in this particular & 28 \\
\hline 9 & specific areas of & 14 & on a particular & 25 \\
\hline 10 & specific heat capacity & 14 & is of particular & 24 \\
\hline 11 & with a specific & 13 & with a particular & 22 \\
\hline 12 & wavelength specific cones & 13 & with particular reference to & 17 \\
\hline 13 & the specific heat & 13 & of this particular & 16 \\
\hline 14 & is specific to & 12 & a particular group & 16 \\
\hline 15 & has a specific & 12 & to the particular & 16 \\
\hline 16 & a specific area & 12 & for this particular & 15 \\
\hline 17 & a very specific & 11 & is a particular & 14 \\
\hline 18 & have a specific & 11 & this particular case & 14 \\
\hline 19 & specific needs of & 11 & in that particular & 13 \\
\hline 20 & a more specific & 11 & a particular way & 12 \\
\hline 21 & with the specific & 10 & on the particular & 12 \\
\hline 22 & for the specific & 10 & particular attention to & 12 \\
\hline 23 & more specific and & 10 & of that particular & 12 \\
\hline 24 & be more specific & 10 & particular emphasis on & 12 \\
\hline 25 & is a specific & 10 & a particular area & 12 \\
\hline 26 & are specific to & 10 & within a particular & 11 \\
\hline-- & & & of particular relevance & 11 \\
\hline-- & & & that a particular & 11 \\
\hline-- & & & particular group of & 11 \\
\hline-- & & & a particular time & 11 \\
\hline-- & & & a particular country & 11 \\
\hline-- & & & of particular importance & 11 \\
\hline-- & & & particular area of & 10 \\
\hline-- & & & a particular form & 10 \\
\hline-- & & & is of particular interest & 10 \\
\hline-- & & & of any particular & 10 \\
\hline-- & & & a particular problem & 10 \\
\hline-- & & & in this particular case & 10 \\
\hline
\end{tabular}


Particular, despite being less frequent in the BAWE corpus, shows a greater potential for creating multiple word clusters in comparison with specific. The adjective specific creates 26 relatively popular three-word clusters, which accounts for $22.76 \%$ (445 tokens) of all its occurrences, whereas particular creates 35 three-word (751 tokens) and 3 four-word clusters (37 tokens), which accounts for $44.64 \%$ ( 788 tokens) of all its occurrences. The difference is statistically significant $[\mathrm{t}(3718)=14.157, \mathrm{p}<0.001, d=0.46]$. As regards 4-word clusters of particular, the highest frequency of 17 occurrences was observed for with particular reference to, followed by 10 occurrences, observed for is of particular interest and in this particular case. In turn, the highest frequency of 4-word clusters of specific was found to be 8 occurrences, observed for the specific needs of, which was below the minimum frequency level set for the analysis.

An analysis of structural variation in the use of 3-word clusters of both adjectives shows that prepositional phrase fragments are the most frequent, with specific creating 10 such clusters ( 238 tokens, $53.48 \%$ of all 3 -word clusters, e.g. with the specific, for the specific, at a specific) and particular creating 20 such clusters (561 tokens, $74.7 \%$, e.g. in a particular, for this particular, within a particular). The next most frequent structures are noun phrase fragments, with specific creating 6 such clusters (77 tokens, 17.3\%, e.g. wavelength specific cones, specific heat capacity, specific needs of) and particular creating 12 such clusters (141 tokens, $18.77 \%$, e.g. a particular way, particular group of, particular emphasis on). These findings confirm the results of previous research which showed that the characteristic phraseology of academic language relies heavily on clusters incorporating parts of noun as well as prepositional phrases (see Biber et al. 1999). Verb phrase components are much less frequent, especially in the case of particular, which creates only two such clusters (38 tokens, 5.05\%), both with the verb form is (i.e. is a particular and is of particular). By comparison, specific creates six 3-word clusters (65 tokens, 14.61\%) with verb phrase fragments including different forms of the verbs be (i.e. is/are specific to, be more specific, is a specific) and have (i.e. has/have a specific). In the four remaining 3-word clusters of specific (65 tokens, 14.61\%) the adjective forms part of an adjectival phrase (e.g. a very specific, a more specific). The remaining 3-word cluster of particular is the clause fragment that a particular with 11 occurrences $(1.46 \%)$.

It can also be seen from Table 5 that $25.39 \%$ (113 tokens) of the 3-word clusters of specific incorporate the definite article, which is significantly more $[\mathrm{t}(1194)=8.275, \mathrm{p}<0.001, \mathrm{~d}=0.49]$ when compared with $7.98 \%$ (60 tokens) of the 3 -word clusters of particular. Actually, this is the only determiner, apart from the indefinite article, with which specific collocates to ensure the correct identification of the following discourse referent. Particular is more varied in this respect, as it also collocates with this (73 tokens, $9.72 \%$ of 3-word clusters) and that (25 tokens, $3.32 \%$ of 3 -word clusters), the pointing function of which is strengthened owing to the presence of the adjective and indicates its "focusing determining" use (Ghesquière 2014: 189). It thus seems that the kind of definiteness that assumes that both the writer and the reader are insiders in terms of academic study 
of their respective field is less evidently involved in the meaning potential of particular than specific (see Biber et al. 1999: 69). Besides, the frequency of occurrence of particular was found to be the greatest in the social science texts (see Table 2) where, as Swales (2005: 9) notes, the presence of this is stronger than in cell biology or medicine, "perhaps reflecting a somewhat more informal writing style." Overall, it seems that specific itself more effectively contributes to the precise description of scientific phenomena. Particular, in turn, is somewhat more reliant on other resources which help to minimize the chances of ambiguity, especially considering that determiners such as this or that serve "to disambiguate antecedents in the previous text" (Wulff et al. 2012: 130).

Another interesting finding is that particular seems to more readily create clusters (approximately 15) which verge on rigid formulaicity of the type that can frequently be found in more general contexts, for example, (in) this particular case, (is) of particular interest, with particular reference to, particular attention to or of particular relevance/importance. The same cannot be said about specific, which tends to create the so-called "classifier-noun sequences" that have their distinct meaning and in academic discourse manifest themselves as "coinages of specialized language use," such as the specific heat, wavelength specific cones or specific heat capacity (Ghesquière 2014: 204). As Vandelanotte (2002: 235) notes, an important feature of such sequences is that they name a subcategory of the head noun, not essentially as a "self-contained, 'self-defining' concept," but rather in opposition to other subcategories, the relevance of which is established by context. They are often part of established taxonomies and thus constitute separate lexical units that can be found in dictionaries where their individual meanings are explained.

As the italicized examples in Table 5 indicate, specific (230 tokens) and particular (381 tokens) share nine 3-word clusters. In 8 cases the adjectives form part of a prepositional phrase fragment and in 1 case they form part of a noun phrase (a specific/particular area). Clusters incorporating prepositional phrase fragments with initial to and at more frequently incorporate the adjective specific (to: 74 tokens, $32.17 \%$ versus 83 tokens, $21.78 \%$; at: 19 tokens, $8.26 \%$ versus 31 tokens, $8.13 \%)$, however, statistical significance was reported $[\mathrm{t}(609)=3.195$, $\mathrm{p}=0.001, d=0.26]$ only for the difference in the frequency of occurrence of to the specific/particular (25 tokens, $10.86 \%$ versus 16 tokens, $4.19 \%$ ). Clusters with initial of more frequently include specific if it is preceded by the definite article the (22 tokens, $9.56 \%$ versus 32 tokens, $8.39 \%$ ), whereas if the article is indefinite, then the following adjective is particular ( 88 tokens, $23.09 \%$ versus 36 tokens, $15.65 \%$ ). This finding is consistent with Polese and D'Avanzo's (2010: 99) observation that particular is "borderline indefinite [...], for it has, as its main feature, fuzzy boundaries." Clusters with initial in, for and with more frequently include the adjective particular (135 tokens, $35.43 \%$ versus 67 tokens, $29.13 \%$ ). Also, the noun phrase fragment $a A D J$ area is relatively more frequent when it includes specific (12 tokens, 5.21\% versus 12 tokens, 3.14\%). 


\subsection{Specific and particular compared}

Figure 2 shows important differences and similarities in the lexico-grammatical profiles of specific and particular in the BAWE corpus. The collocates in green are more closely related to particular, those in red to specific, and those in white tend to combine with both adjectives. The lighter shades of each colour indicate weaker collocations. The grammatical relation between the adjective and its collocate is indicated in blue at the top of each box. The relevant frequencies are presented in the first two columns next to a given collocate, with the left column informing on the frequency of the combination with particular (e.g. particular case: 27 tokens) and the right column informing on the frequency of the combination with specific (e.g. specific case: 9 tokens).

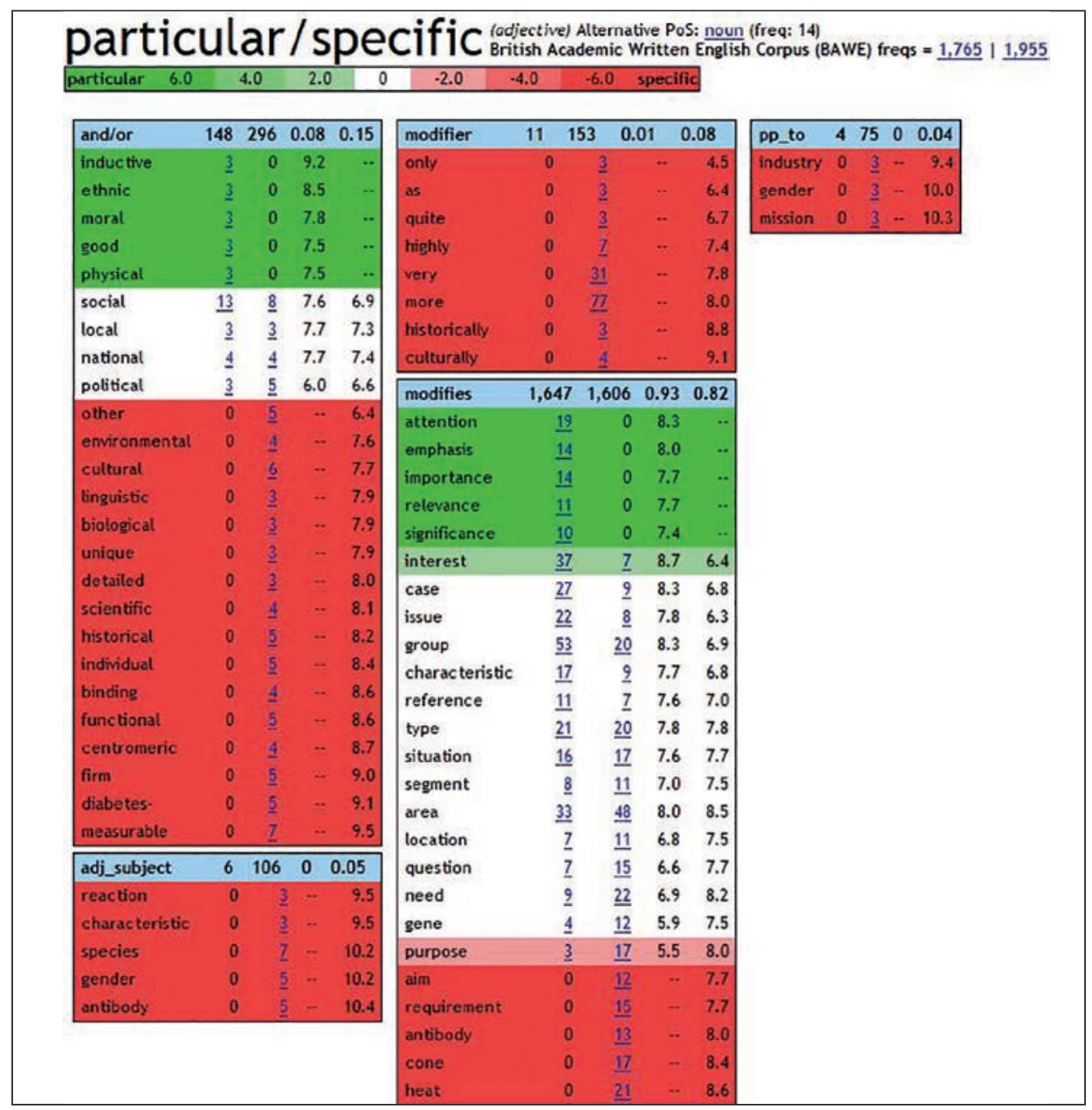

Figure 2. Sketch difference for particular and specific in BAWE 
Specific and particular can serve as contextual near-synonyms in two from among five patterns compared. The typical context they share in academic written English seems to be limited to a nominal phrase, in which particular or specific modifies a noun and can additionally occur in the and/or relation to another adjective: "a particular/specific [(and/or) social/local/national/political] case/ issue/ group/ characteristic/ reference/ type/ situation / segment/area/location/question/need/ gene". The role of the adjectives is to add specificity or detail to entities which, looking at the semantics of the shared noun collocates denoting them, are mostly non-specialized and relevant to any context where they may need to be made more concrete.

Notwithstanding the similarities between the two adjectives in academic written English, there can be noticed significant differences, including also the occurrence of their most salient collocates as the modified noun or in the and/or relation to them. Regarding the nominal collocates, it seems virtually impossible for particular to collocate with aim, requirement, antibody, cone or heat, from among which especially the three final ones denote specialist concepts that have a specified meaning within a given field of study. Instead, it collocates with nouns such as importance, relevance, significance, emphasis and attention, which belong to the 'value' or 'worth' cluster. In thus seems that the possible collocates that accompany particular require specificity that does not necessarily result from the complexity of the context in which they occur (e.g. good, moral), which correlates with Marco's (1998: 47) observation that particular is "a non-technical adjective." In turn, the lexico-grammatical profile of specific is more diverse than that of particular and reveals the definiteness denoted by the adjective as scalar in its nature (see the modifier collocates more, very, highly and quite) as well as context-specific rather than universal (see such salient collocates as centrometric, diabetes or antibody).

\subsection{Words similar to specific and particular in BAWE}

Figures 3 and 4 show words whose grammatical and collocational behaviour is similar to that of specific and particular, respectively. The synonyms listed for each adjective were ordered by similarity, understood as the quality of "shar[ing] most collocates" with either specific or particular (Kilgarriff \& Kosem 2012: 45). 


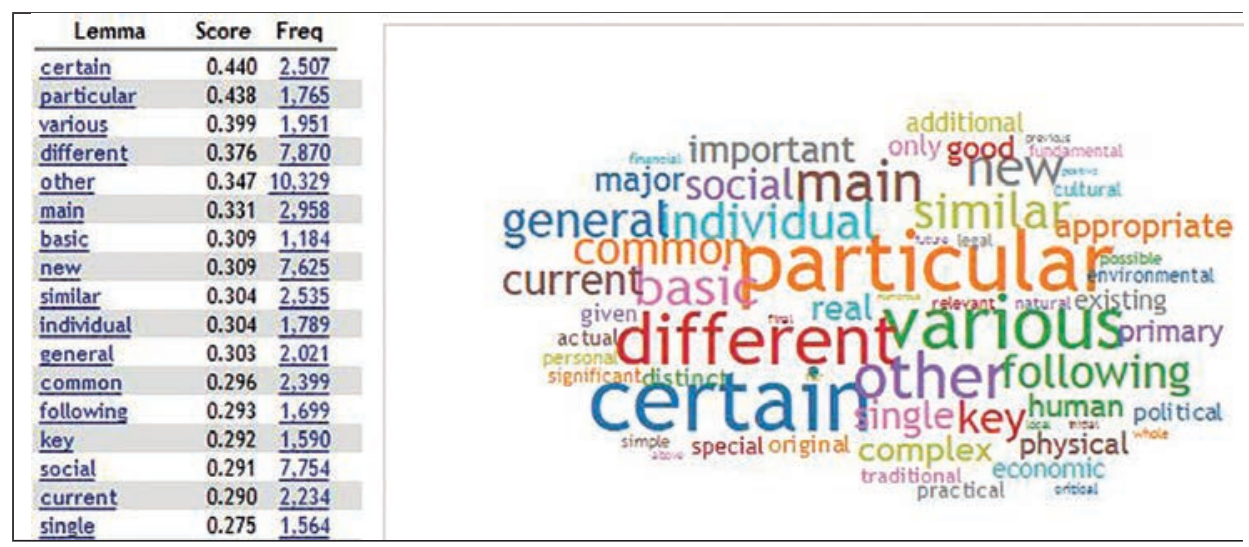

Figure 3. Distributional thesaurus of words similar to specific in BAWE

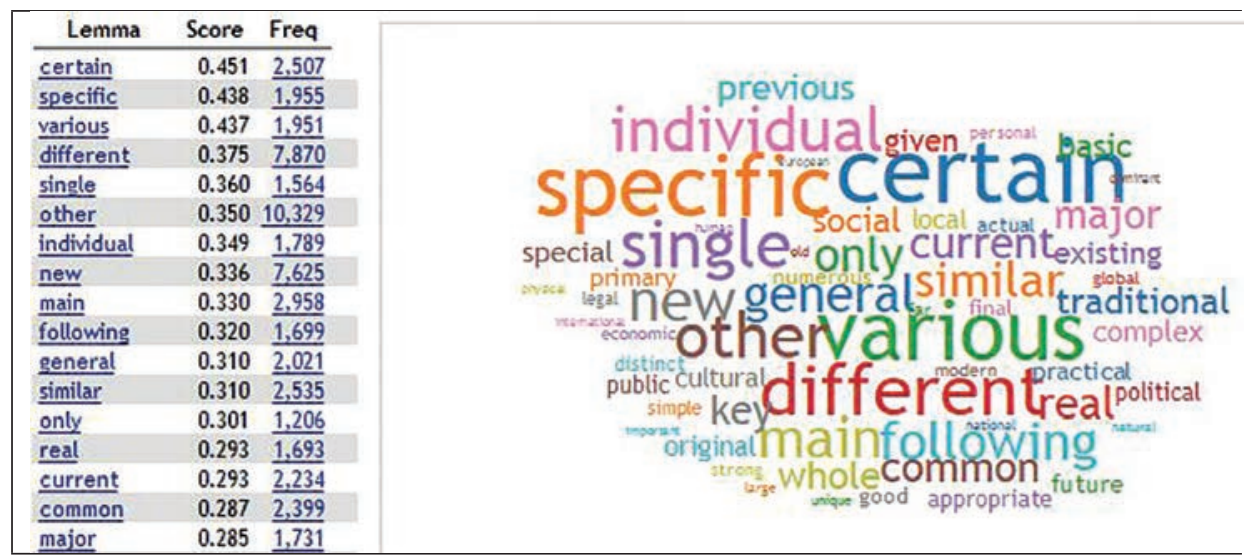

Figure 4. Distributional thesaurus of words similar to particular in BAWE

The list of potential (near)synonyms of both adjectives in academic written English partly overlaps, though the similarity scores for the distinct synonym candidates differ. The words whose meanings are most closely approximated by the senses in which both specific and particular are used in academic written English are exactly the same and include certain, various and different. Interestingly, the second "nearest neighbour" of specific is the adjective particular, which in turn has specific as its second "nearest neighbour" (Kilgarriff et al. 2004: 113). These findings suggest a high degree of semantic overlap between the two adjectives. Actually, among the synonym candidates of specific, only basic, key and social are not listed as the words with which particular shares its collocates. By comparison, real, only and major are the senses which are approximated by particular, but not by specific. Yet, as has been shown in the preceding sections, the interchangeable use of the two adjectives should be carefully considered with regard to the discipline factor and the immediate lexico-grammatical context in which they occur. 


\section{Conclusion}

Adjectives are believed to "add color and zest to stylish scholarly prose" but "can also contribute to clutter," which in the present study has been partly resolved for two specificity adjectives: specific and particular (Sword 2012: 55). The analysis has evidenced that despite semantic similarity between these words, their interchangeability in academic written English is limited. First, specific is the preferred specificity adjective, especially in hard science prose, but its frequency of occurrence decreases in soft science prose, where particular takes precedence. Second, the lexico-grammatical patterns of both words partially overlap but specific appears as more versatile in this regard. It yields ground to particular only in the role of an attributive adjective although the adjectives can serve as contextual near-synonyms when they pre-modify non-technical nouns. Third, specific more readily takes specialized content collocates, whose attributes it often describes as gradable, but less willingly attracts function words. This is reflected in the most frequent clusters of specific, which are less numerous than those of particular, less formulaic but more contentful, as some have individual meanings that are listed in dictionaries. Overall, both adjectives contribute to the semantic narrowing of the concepts and phenomena referred to in academic written English, but each displays its unique lexico-grammatical paths of identification, familiarity with which can facilitate successful academic communication.

The main limitation of the study, which results from its limited scope, is the scarcity of comments and illustrative material that would fully testify to disciplinary differences in the use of the analysed adjectives. Therefore, future research in this respect could more unequivocally identify which lexico-grammatical patterns of particular and specific are preferred within various disciplines to capture their unique meanings.

\section{Notes}

Available from: https://old.sketchengine.co.uk/login/.

The disciplines have been grouped into the four disciplinary areas, following Nesi's (2011:

216-217) BAWE corpus structure.

\section{References}

Ağçam, Reyhan (2014) A corpus-based study on epistemic adjectives in academic English. American Journal of Educational Research 2 (12), 1230-1236.

Ağçam, Reyhan and Mahmut Özkan (2015) A corpus-based study on evaluation adjectives in academic English. Procedia - Social and Behavioral Sciences 199, 3-11.

Bartsch, Sabine (2004) Structural and Functional Properties of Collocations in English: A Corpus Study of Lexical and Pragmatic Constraints on Lexical Co-Occurrence. Tübingen: Narr.

BAWE (British Academic Written English) and BAWE Plus Collections. (2016) Accessed on 25 February 2019 from https://warwick.ac.uk/fac/soc/al/research/collections/bawe/. 
Biber, Douglas, Stig Johansson, Geoffrey Leech, Susan Conrad and Edward Finegan (1999) Longman Grammar of Spoken and Written English. Harlow: Pearson Education Limited.

Biber, Douglas, Susan Conrad and Geoffrey Leech (2002) Longman Student Grammar of Spoken and Written English. Harlow: Pearson Education Limited.

Biber, Douglas, Susan Conrad and Viviana Cortes (2004) 'If you look at...': Lexical bundles in university teaching and textbooks. Applied Linguistics 25, 371-405.

Biber, Douglas (2006) University Language. A corpus-based study of spoken and written registers. Amsterdam, Philadelphia: John Benjamins.

Biber, Dougals and Federica Barbieri (2007) Lexical bundles in university spoken and written registers. English for Specific Purposes 26, 263-286.

Biber, Douglas and Bethany Gray (2016) Grammatical Complexity in Academic English. Cambridge: Cambridge University Press.

Cheng, Winnie, Chris Greaves, John Sinclair and Martin Warren (2009) Uncovering the extent of the phraseological tendency: Towards a systematic analysis of concgrams. Applied Linguistics 30, 236-252.

Cowie, Anthony P. (1992) Multiword lexical units and communicative language teaching. In: Arnaud, Pierre J. L. and Henri Béjoint (eds.) Vocabulary and Applied Linguistics. Palgrave: Macmillan, 1-12.

Coxhead, Averil (2000) A New Academic Word List. TESOL Quarterly 34 (2), 213-238.

De Simone, Flavia, Roberta Presta, Simona Collina and Robert Hartsuiker (2015) On the role of contextual information in the organization of the lexical space. In: Makris, Nikos, Giorgio Bonmassar, Victor Raskin, Julia M. Taylor and Simona Collina (eds.) COGNITIVE 2015: The Seventh International Conference on Advanced Cognitive Technologies and Applications, Nice, France. IARIA, 31-35.

Enç, Mürvet (1991) The semantics of specificity. Linguistic Inquiry 22 (1), 1-25.

Fragaki, Georgia (2009) A corpus-based categorization of Greek adjectives. In: Mahlberg, Michaela, Victorina González-Díaz and Catheirne Smith (eds.) Proceedings of the Corpus Linguistics Conference 2009 (CL2009), Liverpool, 1-19. Accessed on 7 June 2019 from ucrel.lancs.ac.uk/ publications/cl2009/111_FullPaper.doc.

Francis, Gill, Susan Hunston and Elizabeth Manning (1998) Collins COBUILD Grammar Patterns 2: Nouns and Adjectives. London: HarperCollins.

Ghesquière, Lobke (2014) The Directionality of (Inter)subjectification in the English Noun Phrase. Berlin, Boston: De Gruyter Mouton.

Greaves, Chris and Martin Warren (2010) What can a corpus tell us about multi-word units? In: O'Keeffe, Anne and Michael McCarthy (eds.) The Routledge Handbook of Corpus Linguistics. London, New York: Routledge, 212-226.

Hinkel, Eli (2004) Teaching Academic ESL Writing. Practical Techniques in Vocabulary and Grammar. Mahwah NJ: Lawrence Erlbaum Associates.

Hyland, Ken (2015) Corpora and written academic English. In: Biber, Douglas and Randi Reppen (eds.) The Cambridge Handbook of English Corpus Linguistics. Cambridge: Cambridge University Press, 292-308.

Hyland, Ken (2016) General and specific EAP. In: Hyland, Ken and Philip Shaw (eds.) The Routledge Handbook of English for Academic Purposes. London and New York: Routledge, 17-29.

Ionin, Tania (2006) This is definitely specific: specificity and definiteness in article systems. Natural Language Semantics 14, 175-234.

Kilgarriff, Adam, Pavel Rychlý, Pavel Smrz and David Tugwell (2004) The Sketch Engine. In: Williams, Geoffrey and Sandra Vessier (eds.) Proceedings of the 11th EURALEX International Congress. Lorient, France: Université de Bretagne Sud, 105-116.

Kilgarriff, Adam and Iztok Kosem (2012) Corpus tools for lexicographers. In: Granger, Sylviane and Magali Paquot (eds.) Electronic Lexicography. Oxford: Oxford University Press, 31-55.

Kilgarriff, Adam, Vít Baisa, Jan Bušta, Miloš Jakubíček, Vojtěch Kovář, Jan Michelfeit, Pavel Rychlý and Vít Suchomel (2014) The Sketch Engine: ten years on. Lexicography, Journal of Asialex 1 (1), 7-36. 
Lewis, Michael (2000) Teaching collocation: Further developments in the lexical approach. Hove: Language Teaching Publications.

Luzón Marco, María José (1994) Procedural vocabulary as lexical signalling of rethorical function in scientific discourse. Revista Espanola de Linguistica Applicada 10, 161-176.

Luzón Marco, María José (1999) Procedural vocabulary: Lexical signalling of conceptual relations in discourse. Applied linguistics 20 (1), 1-21.

Marco, María José Luzón (1998) Phraseological Patterns in Medical Discourse. The Especialist 19 (1) $41-56$.

Moon, Rosamound (1992) Textual aspects of fixed expressions in learners' dictionaries. In: Arnaud, Pierre J. L. and Henri Béjoint (eds.) Vocabulary and Applied Linguistics. Palgrave: Macmillan, $13-27$.

Morzycki, Marcin (2015) The lexical semantics of adjectives: More than just scales. In: Modification (Key Topics in Semantics and Pragmatics). Cambridge: Cambridge University Press, 13-87.

Nattinger, James R. (1988) Some current trends in vocabulary teaching. In: Carter, Ronald and Michael McCarthy (eds.) Vocabulary and Language Teaching. London and New York: Longman, 62-82.

Nesi, Hilary (2011) BAWE: An introduction to a new resource. In: Frankenberg-Garcia, Ana, Lynne Flowerdew and Guy Aston (eds.) New Trends in Corpora and Language Learning. London: Continuum, 213-228.

O'Keeffe, Anne, Michael McCarthy and Ronald Carter (2007) From Corpus to Classroom. Cambridge: Cambridge University Press.

Okulicz-Kozaryn, Adam (2013) Cluttered writing: Adjectives and adverbs in academia. Scientometrics 96, 679-681.

Oxford English Dictionary on CD-ROM (v. 4.0). 2nd ed. (2009) Oxford: Oxford University Press.

Padró, Muntsa, Marco Idiart, Aline Villavicencio and Carlos Ramisch (2014) Comparing similarity measures for distributional thesauri. In: Calzorali, Nicoletta, Khalid Choukiri, Thierry Declerck, Hrafn Loftsson, Bente Maegaard, Joseph Mariani, Asuncion Moreno, Jan Odijk and Stelios Piperidis (eds.) Proceedings of the Ninth International Conference on Language Resources and Evaluation (LREC-2014). European Languages Resources Association (ELRA), 2964-2971.

Paquot, Magali (2010) Academic Vocabulary in Learner Writing. From Extraction to Analysis. London and New York: Continuum.

Polese, Vanda And Stefania D'Avanzo (2010) Linguistic and legal vagueness in EU directives harmonising protection for refugees and displaced persons. In: Giannoni, Davide S. and Celina Frade (eds.) Researching Language and the Law: Textual Features and Translation Issues. Bern: Peter Lang, 89-112.

Quirk, Randolph, Sidney Greenbaum, Geoffrey Leech and Jan Svartvik (1985) A Comprehensive Grammar of the English Language. London and New York: Longman.

Radziszewski, Adam, Adam Kilgarriff and Robert Lew (2011) Polish Word Sketches. In: Vetulani, Zygmunt (ed.) Human Language Technologies as a Challenge for Computer Science and Linguistics. Proceedings of the 5th Language \& Technology Conference. Poznań: Fundacja Uniwersytetu im. A. Mickiewicza, 237-242.

Rychlý, Pavel (2008) A lexicographer-friendly association score. In: Sojka, Petr and Aleš Horák (eds.) Proceedings of 2nd Workshop on Recent Advances in Slavonic Natural Language Processing, RASLAN 2008. Brno: Masaryk University, 6-9.

Scott, Mike (1996) WordSmith Tools: Manual. Oxford: Oxford University Press.

Scott, Mike (2012) WordSmith Tools version 6. Stroud: Lexical Analysis Software.

Schmitt, Norbert and Ronald Carter (2004) Formulaic sequences in action. In: Norbert Schmitt (ed.) Formulaic Sequences. Amsterdam, Philadelphia: John Benjamins, 1-22.

Simpson, Rita (2004) Stylistic features of academic speech: The role of formulaic expressions. In: Connor, Ulla M. and Thomas Albin Upton (eds.) Discourse in the Professions. Perspectives from Corpus Linguistics. Amsterdam and Philadelphia: John Benjamins, 37-64.

Swales, John and Amy Burke (2003) "It's really fascinating work": Differences in evaluative adjec- 
tives across academic registers. In: Leistyna, Pepi and Charles F. Meyer (eds.) Corpus analysis: Language structure and language use. Amsterdam: Rodopi, 1-18.

Swales, John (2005) Attended and unattended this in academic writing: A long and unfinished story. ESP Malaysia 11, 1-15.

Sword, Helen (2012) Stylish Academic Writing. Harvard, MA: Harvard University Press.

Tognini-Bonelli, Elena (2001) Corpus Linguistics at Work. Amsterdam, Philadelphia: John Benjamins.

Traugott, Elizabeth Closs (2010) Dialogic contexts as motivations for syntactic change. In: Cloutier, Robert A., Anne Marie Hamilton-Brehm and William A. Kretzschmar (eds.) Studies in the History of the English Language V: Variation and Change in English Grammar and Lexicon: Contemporary Approaches. Berlin and New York: de Gruyter Mouton, 11-27.

Tucker, Gordon Howard (1998) The Lexicogrammar of Adjectives A Systemic Functional Approach to Lexis. London and New York: Cassell.

Vandelanotte, Lieven (2002) Prenominal adjectives in English: Structures and ordering. Folia Linguistica 36, 219-259.

Van Roey, Jacques (1990) French-English Contrastive Lexicology: An Introduction. Louvain-laNeuve: Peeters.

Warchał, Krystyna (2015) Certainty and doubt in academic discourse : epistemic modality markers in English and Polish linguistics articles. Katowice: Wydawnictwo Uniwersytetu Śląskiego.

What is the BNC? (2015) Accessed on 25 February 2019 from http://www.natcorp.ox.ac.uk/corpus/ index.xml.

Wray, Alison and Michael R. Perkins (2000) The functions of formulaic language: an integrated model. Language in Communication 20, 1-28.

Wulff, Stefanie, Ute Römer and John Swales (2012) Attended/unattended this in academic student writing: Quantitative and qualitative perspectives. Corpus Linguistics and Linguistic Theory 8 (1), 129-157.

Tatiana Szczyglowska works at the Institute of Neophilology, University of Bielsko-Biala, Poland, where she lectures on translation theory and text analysis to students of English philology. Her main research and teaching interests lie in linguistics and translation with special focus on academic discourse and corpus linguistics. She has also conducted studies in the area of students' attitudes to target language culture and pronunciation.

Address: Tatiana Szczygłowska, Institute of Neophilology, University of Bielsko-Biala, ul. Willowa 2, 43-309 Bielsko-Biała, Poland. [email: tszczyglowska@ath.bielsko.pl] 
